\title{
Anaemia is not a risk factor for progression of acute kidney injury: a retrospective analysis
}

\author{
Jonah Powell-Tuck', Siobhan Crichton², Mario Raimundo ${ }^{3}$, Luigi Camporota ${ }^{4}$, Duncan Wyncoll ${ }^{4}$ \\ and Marlies Ostermann ${ }^{4^{*}}$ (D)
}

\begin{abstract}
Background: In hospitalised patients, anaemia increases the risk of developing acute kidney injury (AKI). Our aim was to determine whether anaemia also has an impact on the risk of progression from early AKI to more severe AKI in critically ill patients.
\end{abstract}

Methods: We retrospectively analysed the data of patients admitted to the adult intensive care unit between 2007 and 2009 who had AKI I as per the AKI Network classification, and who had undergone haemodynamic monitoring within $12 \mathrm{~h}$ of AKI I. We collected baseline characteristics, severity of illness, haemoglobin ( $\mathrm{Hb})$, and haemodynamic parameters in the first $12 \mathrm{~h}$ of AKI I and differentiated between patients who progressed to AKI III and those who did not. Univariate and multivariate logistic regression analyses were used to identify risk factors for progression. Associations between $\mathrm{Hb}$, arterial oxygen saturation and cardiac index were explored by receiver operating characteristic curve analysis.

Results: Two hundred and ten patients (median age 70 years, $68 \%$ male) underwent haemodynamic monitoring within $12 \mathrm{~h}$ of AKI l; 85 (41.5\%) progressed to AKI III. The proportion of patients with underlying cardiac disease was significantly higher among progressors versus non-progressors (58 \% vs $34 \%$, respectively; $p=0.001$ ). On the first day of AKI I, progressors had a significantly higher Sequential Organ Failure Assessment score (9 vs $8 ; p<0.001$ ), lower cardiac index (median 2.6 vs $3.3 \mathrm{~L} / \mathrm{min} / \mathrm{m}^{2} ; p<0.001$ ), higher arterial lactate ( $2 \mathrm{vs} 1.6 \mathrm{mmol} / \mathrm{L} ; p<0.001$ ), higher central venous pressure (16 vs 13; $p=0.02$ ), lower mean arterial blood pressure (median 71 vs $74 \mathrm{mmHg}$; $p=0.01$ ) and significantly higher requirement for cardiovascular and respiratory support, but there was no difference in $\mathrm{Hb}$ concentration (median $96 \mathrm{~g} / \mathrm{L}$ in both groups). Multivariable regression analysis showed that heart disease, need for mechanical ventilation, arterial lactate, Sequential Organ Failure Assessment score, central venous pressure and cardiac index on first day of AKI I were independently associated with progression to AKI III. There was no significant difference in the risk of progression between patients with $\mathrm{Hb} \leq$ or $>80 \mathrm{~g} / \mathrm{L}$, and $\leq$ or $>100 \mathrm{~g} / \mathrm{L}$ on day of AKI I.

Conclusions: In critically ill patients with AKI stage 1, anaemia was not associated with an increased risk of progression to more severe AKI.

Keywords: Acute kidney injury, Haemoglobin, Anaemia, Renal recovery

\footnotetext{
* Correspondence: Marlies.Ostermann@gstt.nhs.uk

${ }^{4}$ Department of Critical Care, King's College London, Guy's \& St Thomas'

Foundation Hospital, London, UK

Full list of author information is available at the end of the article
} 


\section{Background}

Acute kidney injury (AKI) is a common complication of critical illness, affecting more than $50 \%$ of patients admitted to intensive care units (ICUs) $[1,2]$. There is a clear association between severity of AKI and risk of short and long-term complications, including death and development of chronic kidney disease [3,4]. Management of AKI is supportive with focus on correction of volume depletion, haemodynamic optimisation and avoidance of further nephrotoxic insults. It is advised that management is tailored to AKI stage, including early use of haemodynamic monitoring [5], with the aims to reverse the injurious process within the kidneys, to induce renal recovery and to prevent progression to severe AKI.

We recently reported that a lower mean arterial pressure (MAP), reduced systemic oxygen delivery and increased fluid administration were independently associated with a higher risk of progression from AKI stage I to AKI stage III $[6,7]$. However, it is unknown whether anaemia is also a risk factor. This is an important question for several reasons, since:

1. Anaemia is very common during critical illness and blood transfusions are often withheld until haemoglobin $(\mathrm{Hb})$ is reduced to $<70-80 \mathrm{~g} / \mathrm{L}$ based on large randomised controlled trials which showed no survival benefit in patients with a higher $\mathrm{Hb}$ [8-10].

2. Hb is a key contributor to oxygen delivery.

3. Anaemia is a risk factor for the development of AKI in hospitalised patients [11], after major surgery [12-17] and following cardiac procedures [18, 19].

4. In patients undergoing cardiopulmonary bypass surgery, haemodilution to a haematocrit of $<24 \%$ is associated with an increased risk of postoperative AKI [20].

5. In patients with chronic kidney disease (CKD), correction of anaemia has been shown to slow the progression of renal failure [21, 22].

6. In patients undergoing cardiac surgery, a single-dose erythropoietin (EPO) administered before surgery resulted in significant reduction in postoperative AKI [23, 24].

The aim of this study was to determine whether anaemia has an impact on the risk of progression from early AKI to more severe AKI during critical illness. We hypothesised that critically ill patients with AKI and a low $\mathrm{Hb}$ had a reduced chance of renal recovery compared to AKI patients with a higher $\mathrm{Hb}$.

\section{Methods}

We retrospectively reviewed an electronic database (CareVue, Philips) containing data from all patients admitted to Guy's \& St Thomas' NHS Trust ICU between July
2007 and June 2009, and identified those with AKI stage I as per serum creatinine criteria of the AKI Network (AKIN) classification [25] in whom advanced haemodynamic monitoring had been initiated for clinical reasons within $12 \mathrm{~h}$ of the patient meeting the criteria for AKI stage I. Renal transplant patients, re-admissions and patients who left the ICU within $24 \mathrm{~h}$ of diagnosis of AKI I or developed AKI stage III within $12 \mathrm{~h}$ of diagnosis of AKI I were excluded. The outcome of interest was progression to AKI stage III as defined by the AKIN classification, i.e. rise of serum creatinine greater than threefold from baseline or to $\geq 354 \mu \mathrm{mol} / \mathrm{L}$ with an acute rise of $\geq 44 \mu \mathrm{mol} / \mathrm{L}$, or requirement for renal replacement therapy (RRT) [25]. The methods have been described in more detail elsewhere [6,7].

\section{Data collection}

We recorded demographics, comorbidities, diagnosis, Acute Physiology and Chronic Health Evaluation (APACHE) II score and Sequential Organ Failure Assessment (SOFA) score on admission to ICU and first available cardiac index, contemporaneous arterial oxygen saturation $\left(\mathrm{SaO}_{2}\right), \mathrm{Hb}$, arterial lactate, central venous pressure (CVP), MAP and urine output during the first $12 \mathrm{~h}$ period after diagnosis of AKI I. We also recorded SOFA score, 24-h urine output, cumulative fluid balance, need for mechanical ventilation and cardiovascular support, and presence of sepsis (as per current consensus criteria [26]) on day of AKI I. Systemic oxygen delivery index $\left(\mathrm{DO}_{2} \mathrm{I}\right)$ was calculated as $\mathrm{DO}_{2} \mathrm{I}=1.34 \times \mathrm{Hb} \times \mathrm{SaO}_{2} \times$ cardiac index.

\section{Statistical analysis}

Categorical variables were summarised as frequency (percentage). SOFA scores were summarised as mean and standard deviation (SD) and all other continuous variables, which were not normally distributed, summarised as median and interquartile range (IQR). Characteristics were compared between patients who did and did not progress using Chi-square, Fisher's exact, Mann-Whitney or $t$-tests, as appropriate.

Associations between components of the $\mathrm{DO}_{2} \mathrm{I}(\mathrm{Hb}$, $\mathrm{SaO}_{2}$ and cardiac index) were explored using receiver operating characteristic (ROC) curves. The area under the curve (AUC) was used to compare the ability of the three parameters to predict which patients progressed.

To determine which components of $\mathrm{DO}_{2} \mathrm{I}$ (i.e. $\mathrm{Hb}, \mathrm{SaO}_{2}$ and cardiac index) were most strongly associated with progression, multivariable logistic regression models were used. In addition to the three parameters, any factors which were found to be significant in univariate analyses (mechanical ventilation, coronary artery disease (CAD)/ congestive cardiac failure (CCF), lactate, SOFA score on day of AKI I, CVP and mean MAP in the 12-h period after 
diagnosis of AKI, urine output) were also included in the model. In additional analyses, sepsis on day of AKI I was added to the model and tests for interactions between sepsis and $\mathrm{CAD} / \mathrm{CCF}$ and $\mathrm{Hb}, \mathrm{SaO}_{2}$ and cardiac index were performed to determine whether there were differences in risk of progression in patients with $\mathrm{CAD} / \mathrm{CCF}$ or sepsis.

The sensitivity and specificity associated with cut-off points of $\mathrm{Hb}$ above and below 80 and $100 \mathrm{~g} / \mathrm{L}$ were also calculated. The differences in odds of progression for patients in the two groups were compared using logistic regression models.

\section{Ethics}

The study had institutional approval by the Clinical Governance Department in the hospital. As per Governance Arrangements for Research Ethics Committees published by the UK Health Departments, formal review by a Research Ethics Committee and need for individual informed consent was not required since the research was limited to secondary use of information previously collected in the course of normal care and the patients were not identifiable to the research team carrying out the research [27].

\section{Results}

Of 2118 patients admitted to the ICU in the 2-year period, 790 (37\%) had AKI stage I; 69 patients had exclusion criteria and a further 511 patients were excluded because they did not have haemodynamic monitoring performed within the first $12 \mathrm{~h}$ of AKI I. The remaining 210 patients were included in the analysis (Table 1). The median number of days between ICU admission and AKI I was 1 (IQR 0-22).

Of 85 patients (41\%) who progressed to AKI III, 78 (92\%) received RRT. The mean duration between AKI I and AKI III was 2.6 days (SD 3.4); the median duration was 2 days (IQR 1-2). Five patients with AKI I died before their renal function recovered or progressed. The remaining 120 patients with AKI I recovered renal function.

\section{Risk factors for progression to AKI stage III}

Patients with AKI I who progressed to AKI III were sicker on the day of AKI I as evidenced by a higher SOFA score, higher arterial lactate level, lower MAP and greater need for respiratory and cardiovascular support (Table 2). There was no difference in the $\mathrm{Hb}$ concentration of those who progressed to AKI III and those who did not progress. Multivariable regression analysis showed that underlying heart disease (CAD and/or CCF), need for mechanical ventilation, arterial lactate, SOFA score and CVP on day of AKI I were independent risk factors for progression from AKI I to AKI III (Table 3). A higher cardiac index was independently associated with a reduced risk.
Table 1 Baseline characteristics of patients with AKI I

\begin{tabular}{ll}
\hline Parameter & Total $(n=210)$ \\
\hline Age, median (IQR) & $70(57-77)$ \\
Male gender, n (\%) & $142(68)$ \\
Comorbidities & \\
CAD/CCF, n (\%) & $92(44)$ \\
Chronic hypertension, n (\%) & $81(39)$ \\
Diabetes mellitus, n (\%) & $40(19)$ \\
Malignancy, n (\%) & $28(13)$ \\
COPD, n (\%) & $27(13)$ \\
CKD, n (\%) & $25(12)$ \\
Neurological disease, n (\%) & $23(11)$ \\
Chronic liver disease, n (\%) & $12(6)$ \\
Admission diagnosis & \\
Post-surgery, n (\%) & $72(34)$ \\
Cardiac, n (\%) & $54(26)$ \\
Sepsis, n (\%) & $38(18)$ \\
Respiratory, n (\%) & $34(16)$ \\
Other, n (\%) & $12(6)$ \\
Severity of illness on admission to ICU & $18(14-22)$ \\
APACHE II score, median (IQR) & $7.1(2.8)$ \\
SOFA score, mean (SD) & \\
\hline
\end{tabular}

AKI acute kidney injury, APACHE Acute Physiology and Chronic Health Evaluation, CAD coronary artery disease, CCF congestive cardiac failure, $C K D$ chronic kidney disease, COPD chronic obstructive pulmonary disease, ICU intensive care unit, IQR interquartile range, SD standard deviation, SOFA Sequential Organ Failure Assessment

\section{Impact of anaemia}

Figure 1 shows the ROC curves summarising the association between $\mathrm{Hb}, \mathrm{SaO}_{2}$, cardiac index and progression to AKI III. Only cardiac index appeared to differentiate between progressors and non-progressors. There was no particular cut-off for $\mathrm{Hb}$ for progression. When choosing $80 \mathrm{~g} / \mathrm{L}$ and $100 \mathrm{~g} / \mathrm{L}$ as clinically meaningful cut-offs, there was no significant difference in the risk of progression to AKI stage III between patients with $\mathrm{Hb}<80 \mathrm{~g} / \mathrm{L}$ on day of AKI I and those with a higher $\mathrm{Hb}$ or patients with a $\mathrm{Hb}$ below or above $100 \mathrm{~g} / \mathrm{L}$ (Table 4). There was also no difference in the impact of $\mathrm{Hb}$ levels on progression in patients with or without underlying heart disease (CAD and/ or $\mathrm{CCF}$ ) and between patients with or without sepsis.

\section{Discussion}

We previously demonstrated that a higher systemic $\mathrm{DO}_{2} \mathrm{I}$ was independently associated with a reduced risk of progression from AKI stage I to AKI stage III. In this study we analysed the components of $\mathrm{DO}_{2} \mathrm{I}$ individually and found that haemoglobin concentration was not independently associated with AKI progression. Instead, the need for mechanical ventilation, the presence of underlying cardiac disease, raised lactate, higher SOFA 
Table 2 Comparison of AKI progressors and non-progressors

\begin{tabular}{|c|c|c|c|c|}
\hline Parameters & All $(n=210)^{*}$ & Did not progress to AKI III $(n=120)$ & Progressed to AKI III $(n=85)$ & $p$ value \\
\hline Age, median (IQR) & $70.5(57-77)$ & $70(54-76)$ & $71(60-78)$ & 0.13 \\
\hline Male gender, n (\%) & $138(67.3)$ & $79(65.8)$ & $59(69.4)$ & 0.59 \\
\hline CAD/CCF, n (\%) & $92(44)$ & $41(34.2)$ & $49(57.7)$ & 0.001 \\
\hline \multicolumn{5}{|l|}{ Severity of illness on admission to ICU } \\
\hline SOFA score, mean (SD) & $7.1(2.8)$ & $6.9(2.7)$ & $7.5(2.9)$ & 0.14 \\
\hline APACHE II score, median (IQR) & $18(14-22)$ & $17(13-21)$ & $18(15-22)$ & 0.09 \\
\hline \multicolumn{5}{|l|}{ Parameters on day of AKI I } \\
\hline SOFA score, mean (SD) & $8.7(2.7)$ & $8.0(2.5)$ & $9.6(2.8)$ & $<0.001$ \\
\hline Presence of sepsis, n (\%) & $125(60)$ & $79(66.4)$ & $43(50.6)$ & 0.02 \\
\hline $\mathrm{DO}_{2} \mathrm{I}\left(\mathrm{ml} / \mathrm{min} / \mathrm{m}^{2}\right)$, median (IQR) & $362(277-482)$ & $405(302-514)$ & $325(266-401)$ & $<0.001$ \\
\hline $\mathrm{SaO}_{2}$ & $0.95(0.94-0.96)$ & $0.95(0.94-0.96)$ & $0.95(0.94-0.96)$ & 0.81 \\
\hline $\mathrm{Hb}(\mathrm{g} / \mathrm{L})$, median (IQR) & $96(88-105)$ & $96(90-105)$ & $96(85-105)$ & 0.64 \\
\hline Cardiac index $\left(\mathrm{L} / \mathrm{min} / \mathrm{m}^{2}\right)$, median (IQR) & $3.0(2.3-3.9)$ & $3.3(2.5-4.2)$ & $2.6(2.1-3.3)$ & $<0.001$ \\
\hline Arterial lactate (mmol/L), median (IQR) & $1.8(1.3-2.6)$ & $1.6(1.1-2.3)$ & $2(1.5-3)$ & $<0.001$ \\
\hline CVP $\left(\mathrm{cmH}_{2} \mathrm{O}\right)$, median $(\mathrm{IQR})$ & $14(10-18)$ & $13(10-17)$ & $16(11-19)$ & 0.02 \\
\hline MAP (mmHg), median (IQR) & $73(69-78)$ & $74(70-79)$ & $71(68-77)$ & 0.01 \\
\hline Vasopressor/inotrope therapy, n (\%) & $187(8)$ & $100(83.3)$ & $82(96.5)$ & 0.003 \\
\hline Mechanical ventilation, n (\%) & $191(91)$ & $103(85.8)$ & $84(98.8)$ & 0.001 \\
\hline Urine output (mL/h), median (IQR) & $61(38-94)$ & $66(46-104)$ & $54(32-79)$ & 0.002 \\
\hline Cumulative fluid balance (ml), median (IQR) & $2361(952-3812)$ & $2379(935-4222)$ & $2363(974-3719)$ & 0.995 \\
\hline \multicolumn{5}{|l|}{ Outcome } \\
\hline ICU mortality, \% & 32.4 & 11.7 & 57.6 & $<0.001$ \\
\hline Hospital mortality, \% & 43.3 & 24.2 & 67.1 & $<0.001$ \\
\hline
\end{tabular}

*Including 5 patients who died before their renal function recovered or progressed

AKI acute kidney injury, APACHE Acute Physiology and Chronic Health Evaluation, CAD coronary artery disease, CCF congestive cardiac failure, CVP central venous pressure, $D_{2}$ I systemic oxygen delivery index, ICU intensive care unit, IQR interquartile range, $H b$ haemoglobin, $M A P$ mean arterial pressure, SaO $\mathrm{O}_{2}$ arterial oxygen saturation, SD standard deviation, SOFA Sequential Organ Failure Assessment

Table 3 Multivariable logistic regression models for progression

\begin{tabular}{lrll}
\hline Parameters on day of AKI I & OR & $95 \% \mathrm{Cl}$ & $p$ value \\
\hline Mechanical ventilation & 22.12 & $2.40-205.52$ & 0.006 \\
CAD/CCF & 3.17 & $1.55-6.49$ & 0.002 \\
Arterial lactate $(\mathrm{mmol} / \mathrm{L})$ & 1.57 & $1.15-2.13$ & 0.004 \\
SOFA score & 1.21 & $1.04-1.39$ & 0.01 \\
$\mathrm{CVP}\left(\mathrm{CmH}_{2} \mathrm{O}\right)$ & 1.07 & $1.01-1.14$ & 0.02 \\
$\mathrm{Cardiac}$ index $\left(\mathrm{L} / \mathrm{min} / \mathrm{m}^{2}\right)$ & 0.69 & $0.50-0.96$ & 0.03 \\
$\mathrm{MAP}(\mathrm{mmHg})$ during $12 \mathrm{~h}$ post-AKI I & 0.97 & $0.92-1.02$ & 0.18 \\
$\mathrm{Hb}(\mathrm{g} / \mathrm{L})$ & 0.82 & $0.65-1.03$ & 0.09 \\
$\mathrm{SaO}$ & 0.97 & $0.79-1.20$ & 0.79 \\
\hline
\end{tabular}

AKI acute kidney injury, CAD coronary artery disease, CCF congestive cardiac failure, $\mathrm{Cl}$ confidence interval, $\mathrm{CVP}$ central venous pressure, $\mathrm{Hb}$ haemoglobin, MAP mean arterial pressure, $\mathrm{OR}$ odds ratio, $\mathrm{SaO}_{2}$ arterial oxygen saturation, SOFA Sequential Organ Failure Assessment score and a higher CVP were all independent risk factors for progression; a higher cardiac index was independently associated with a reduced risk of progression.

The relationship between anaemia and AKI is not fully understood. It is well known that AKI can contribute to the development of anaemia as a result of reduced EPO production, an increased risk of bleeding and reduced red cell life span [28]. It has also been demonstrated that anaemia is a risk factor for the development of AKI in patients undergoing major surgery leading to increased mortality [12, 14, 15]. However, it is not always clear whether the presence of anaemia is simply a reflection of co-morbid disease that increases the risk of AKI or a direct contributor to AKI, for instance as a result of anaemia-induced hypoxia in the renal cortex. The kidney, particularly the proximal tubule, is known to be very susceptible to ischaemic injury [29]. Using an animal model, Darby et al. showed a sustained reduction in renal cortical and medullary oxygenation in rats which were subjected to $1 \mathrm{~h}$ of normothermic cardiopulmonary bypass with target $\mathrm{Hb}$ concentrations of $65 \mathrm{~g} / \mathrm{L}$ [30]. 


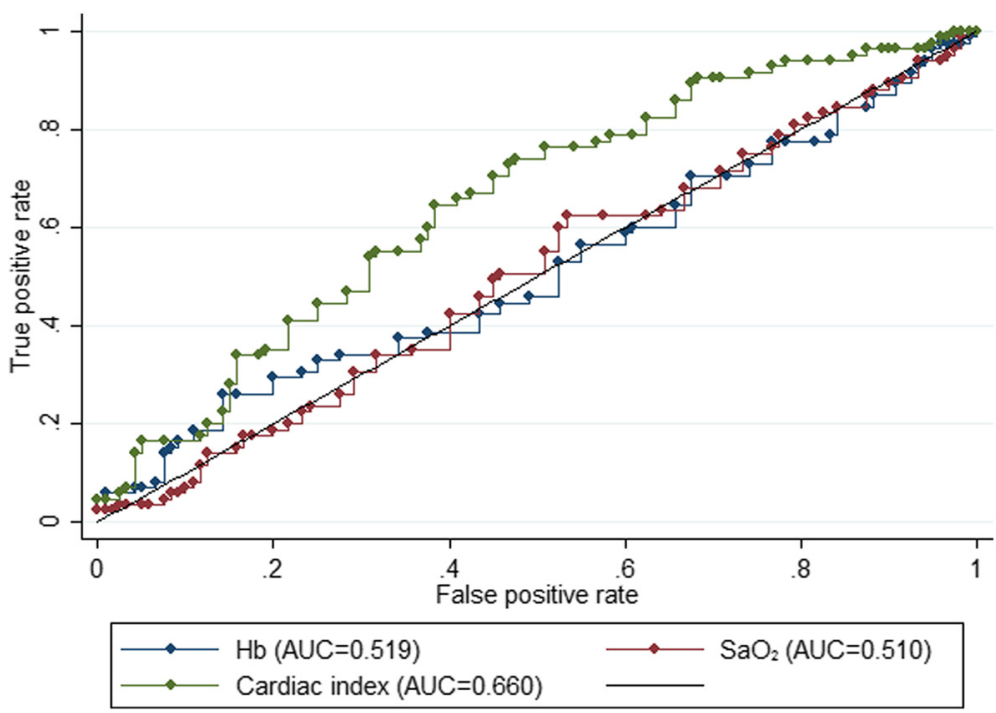

Fig. 1 Receiver operating characteristic curves for progression to AKI stage III. AUC area under the curve, $\mathrm{Hb}$ haemoglobin, $\mathrm{SaO}_{2}$ arterial oxygen saturation

Lastly, blood transfusions in patients with AKI receiving RRT have not been shown to have an impact on 90-day mortality or other patient-centred outcomes [31].

To the best of our knowledge, the question whether anaemia affects the chances of renal recovery has only been explored once before in a retrospective study of 211 hospitalised patients [32]. The authors defined AKI by the following: $0.5 \mathrm{mg} / \mathrm{dL}$ increase in serum creatinine if the baseline serum creatinine was $\leq 1.9 \mathrm{mg} / \mathrm{dL} ; 1.0 \mathrm{mg} /$ $\mathrm{dL}$ increase for baseline serum creatinine $2.0-4.9 \mathrm{mg} / \mathrm{dL}$; $1.5 \mathrm{mg} / \mathrm{dL}$ increase if baseline serum creatinine was $\geq 5.0 \mathrm{mg} / \mathrm{dL}$. Renal recovery was defined by complete or near complete return of the creatinine to baseline, $50 \%$ reduction in creatinine from the peak creatinine, or discontinuation of RRT. The study showed that neither renal recovery nor survival differed among patients with mild versus severe anaemia as measured by fall in $\mathrm{Hb}$ or nadir $\mathrm{Hb}$. Although we defined AKI differently, and focussed on progression from AKI stage I to AKI stage III versus non-progression, our study reaches a similar conclusion. Using two separate haemoglobin cut-offs, we found that the risk of progression was not increased in patients with AKI I and $\mathrm{Hb}<80$ or $\mathrm{Hb}<100 \mathrm{~g} / \mathrm{L}$. The previously demonstrated association between $\mathrm{DO}_{2} \mathrm{I}$ and
AKI progression [6] was predominantly determined by underlying cardiac index but not $\mathrm{Hb}$ or $\mathrm{SaO}_{2}$. Of note, we previously also found that once AKI was established, attempts to increase a low $\mathrm{DO}_{2} \mathrm{I}$ did not prevent progression to AKI III [6] and excessive fluid administration resulting in fluid accumulation was associated with an increased risk of progression [7].

Given the high prevalence of anaemia in critically ill patients, restrictive transfusion strategies and the high incidence of AKI in critically ill patients, these results are important. Nevertheless, some unanswered questions remain. Firstly, we retrospectively analysed the data of critically ill patients with AKI only in those where haemodynamic monitoring was considered to be required. Whether anaemia affects renal recovery in patients who are less sick is not clear. Second, we defined AKI by the creatinine and RRT criteria of the AKIN classification only [25]. It is possible that the association between anaemia and progression to AKI III would have been different if we had also used the urine criteria to identify patients with AKI. Third, we were not able to explore whether blood transfusion was a risk factor for progression of AKI. A recent retrospective study in patients with moderate anaemia showed an increased

Table 4 Impact of different haemoglobin cut-offs on day of AKI I on risk of progression to AKI III

\begin{tabular}{|c|c|c|c|c|c|c|c|}
\hline $\mathrm{Hb}$ on day of $\mathrm{AKI} I$ & $n$ & Progression to AKI III, n (\%) & Sensitivity & Specificity & $O R^{*}$ & $95 \% \mathrm{Cl}$ & $p$ value \\
\hline$>80 \mathrm{~g} / \mathrm{L}$ & 190 & $78(41.0)$ & $8.2 \%$ & $93.3 \%$ & 1 & & \\
\hline$\leq 80 \mathrm{~g} / \mathrm{L}$ & 15 & $7(46.7)$ & & & 2.05 & $0.58-7.12$ & 0.27 \\
\hline$>100 \mathrm{~g} / \mathrm{L}$ & 134 & $55(41.0)$ & $64.7 \%$ & $34.2 \%$ & 1 & & \\
\hline$\leq 100 \mathrm{~g} / \mathrm{L}$ & 71 & $30(42.3)$ & & & 1.40 & $0.70-2.83$ & 0.35 \\
\hline
\end{tabular}

*Adjusted for arterial oxygen saturation, cardiac index, mechanical ventilation, coronary artery disease/congestive cardiac failure, arterial lactate, Sequential Organ Failure Assessment score, central venous pressure and mean arterial pressure

$A K I$ acute kidney injury, $\mathrm{Cl}$ confidence interval, $\mathrm{Hb}$ haemoglobin, $\mathrm{OR}$ odds ratio 
incidence of AKI in those who were transfused [33]. We cannot exclude that the theoretical benefits of a higher $\mathrm{Hb}$ were counteracted by adverse effects from blood transfusions. Fourth, we did not determine the aetiology of anaemia and explore whether it was acute or chronic. Also, we did not correct $\mathrm{Hb}$ levels for fluid accumulation but note that there was no difference in cumulative fluid balance on the day of AKI I. Fifth, we acknowledge that our results may contradict those studies which showed less AKI in cardiac surgery patients who had received EPO treatment preoperatively $[23,24]$. However, it is possible that these effects were not simply due to correction of $\mathrm{Hb}$ but also prevention of blood transfusion and other EPO-related organ protective effects, including inhibition of apoptosis [34]. Finally, we analysed data from 2007 to 2009 which included relatively few patients with $\mathrm{Hb}<80 \mathrm{~g} / \mathrm{L}$. The cohort may have been too small to detect a potential association between severe anaemia and AKI progression.

\section{Conclusions}

Our study shows that, whilst a low cardiac index on the first day of AKI was associated with progression to more severe AKI, anaemia was not. Unanswered questions remain and further investigation is warranted. Until such time, clinicians should prioritise optimisation of cardiac index to reduce the risk of progression of AKI, but there is no evidence that a higher $\mathrm{Hb}$ confers protection.

\section{Key messages}

- In critically ill patients with acute kidney injury (AKI) stage I, the mean haemoglobin on the first day of AKI was $96 \mathrm{~g} / \mathrm{L}$.

- There was no difference in the haemoglobin concentration of patients who progressed to AKI III and those who did not progress.

- Pre-existing heart disease, need for mechanical ventilation, arterial lactate, SOFA score, central venous pressure and cardiac index on the first day of AKI stage I were independently associated with an increased risk of progression from AKI stage I to AKI stage III but haemoglobin was not.

\footnotetext{
Abbreviations

AKI: Acute kidney injury; AKIN: Acute Kidney Injury Network; APACHE: Acute Physiology and Chronic Health Evaluation; AUC: Area under the curve; CAD: Coronary artery disease; CCF: Congestive cardiac failure; CKD: Chronic kidney disease; CVP: Central venous pressure; $\mathrm{DO}_{2}$ l: Oxygen delivery index; EPO: Erythropoetin; Hb: Haemoglobin; ICU: Intensive care unit; IQR: Interquartile range; MAP: Mean arterial pressure; ROC: Receiver operating characteristic; RRT: Renal replacement therapy; $\mathrm{SaO}_{2}$ : Arterial oxygen saturation; SD: Standard deviation; SOFA: Sequential Organ Failure Assessment.
}

\section{Competing interests}

The authors declare that they have no competing interests.

\section{Authors' contributions}

JPT interpreted the data and wrote the first draft; SC performed the statistical analysis; MR collected the data and helped revise the manuscript; LC helped interpreting the data and contributed to the revision of the manuscript; DW helped interpreting the data and contributed to the revision of the manuscript; $\mathrm{MO}$ designed and led the project and is accountable for all aspects of the work. All authors participated sufficiently in the work and read and approved the final version of the manuscript.

\section{Acknowledgements}

The authors wish to thank Yadullah Syed and John R. Martin for assisting with the data acquisition.

\section{Author details}

'Department of Critical Care, Guy's \& St Thomas' Foundation Hospital, London, UK. 'Division of Health and Social Care Research, King's College London, London, UK. ${ }^{3}$ Hospital de Santa Maria, Centro Hospitalar Lisboa Norte, Lisbon, Portugal. ${ }^{4}$ Department of Critical Care, King's College London, Guy's \& St Thomas' Foundation Hospital, London, UK.

Received: 6 December 2015 Accepted: 10 February 2016

Published online: 08 March 2016

\section{References}

1. Hoste EA, Bagshaw SM, Bellomo R, Cely CM, Colman R, Cruz DN, et al. Epidemiology of acute kidney injury in critically ill patients: the multinational AKI-EPI study. Intensive Care Med. 2015;41(8):1411-23.

2. Mandelbaum T, Scott DJ, Lee J, Mark RG, Malhotra A, Waikar SS, et al. Outcome of critically ill patients with acute kidney injury using the Acute Kidney Injury Network criteria. Crit Care Med. 2011;39:2659-64.

3. Murugan R, Kellum JA. Acute kidney injury: what's the prognosis? Nat Rev Nephrol. 2011;7:209-17.

4. Chawla LS, Eggers PW, Star RA, Kimmel PL. Acute kidney injury and chronic kidney disease as interconnected syndromes. N Engl J Med. 2014;371(1):58-66

5. Kidney Disease: Improving Global Outcomes (KDIGO) Acute Kidney Injury Work Group. KDIGO clinical practice guideline for acute kidney injury. Kidney Int. 2012;2:1-138.

6. Raimundo M, Crichton S, Syed Y, Martin JR, Beale R, Treacher D, et al. Low systemic oxygen delivery and blood pressure and risk of progression of early acute kidney injury. Clin J Am Soc Nephrol. 2015;10(8):1340-9.

7. Raimundo M, Crichton S, Martin JR, Syed Y, Varrier M, Wyncoll D, et al. Increased fluid administration after early acute kidney injury is associated with less renal recovery. Shock. 2015;44(5):431-7.

8. Holst LB, Petersen MW, Haase N, Perner A, Wetterslev J. Restrictive versus liberal transfusion strategy for red blood cell transfusion: systematic review of randomised trials with meta-analysis and trial sequential analysis. BMJ. 2015;350:h1354.

9. Hébert PC, Wells G, Blajchman MA, Marshall J, Martin C, Pagliarello G, et al. A multicenter, randomized, controlled clinical trial of transfusion requirements in critical care. Transfusion Requirements in Critical Care Investigators, Canadian Critical Care Trials Group. N Engl J Med. 1999;340(60):409-17.

10. Marik PE, Corwin HL. Efficacy of red blood cell transfusion in the critically ill: a systematic review of the literature. Crit Care Med. 2008;36:2667-74.

11. Shema-Didi L, Ore L, Geron R, Kristal B. Is anemia at hospital admission associated with in-hospital acute kidney injury occurrence? Nephron Clin Pract. 2010;115(2):c168-76.

12. Fowler AJ, Ahmad T, Phull MK, Allard S, Gillies MA, Gearse RM. Meta-analysis of the association between preoperative anaemia and mortality after surgery. Br J Surg. 2015;102(11):1314-24.

13. Choi YJ, Kim SO, Sim JH, Hahm KD. Postoperative anemia is associated with acute kidney injury in patients undergoing total hip replacement arthroplasty: a retrospective study. Anesth Analg. 2015; Oct 8 (Epub ahead of print). doi:10. 1213/ANE.0000000000001003.

14. Najjar M, Salna M, George I. Acute kidney injury after aortic valve replacement: incidence, risk factors and outcomes. Expert Rev Cardiovasc Ther. 2015;13(3):301-16.

15. Karkouti K, Wijeysundera DN, Yau TM, Callum JL, Cheng DC, Crowther M, et al. Acute kidney injury after cardiac surgery: focus on modifiable risk factors. Circulation. 2009;119:495-502. 
16. De Santo L, Romano G, Della Corte A, de Simone V, Grimaldi F, Cotrufo M, et al. Preoperative anemia in patients undergoing coronary artery bypass grafting predicts acute kidney injury. J Thorac Cardiovasc Surg. 2009;138(4):965-70.

17. Karkouti K, Grocott HP, Hall R, Jessen ME, Kruger C, Lemer AB, et al. Interrelationship of preoperative anemia intraoperative anemia, and red blood cell transfusion as potentially modifiable risk factors for acute kidney injury in cardiac surgery: a historical multicentre cohort study. Can J Anaesth. 2015;62(4):377-84.

18. Arai T, Morice MC, O'Connor SA, Yamamoto M, Eltchaninoff H, Leguerrier A, et al. FRANCE 2 Registry Investigators. Impact of pre- and post-procedural anemia on the incidence of acute kidney injury and 1-year mortality in patients undergoing transcatheter aortic valve implantation (from the French Aortic National CoreValue and Edwards 2 [FRANCE 2] Registry. Catheter Cardiovasc Intev. 2015;85(7):1231-9.

19. Shacham Y, Cal-Oz A, Leshem-Rubinow E, Arbel Y, Flint N, Keren G, et al: Association of admission haemoglobin levels and acute kidney injury among myocardial infarction patients treated with primary percutaneous intervention. Can J Cardiol. 2015;31(1):50-5.

20. Habib RH, Zacharias A, Schwann TA, Riordan CJ, Engoren M, Durham SJ, et al. Role of hemodilutional anemia and transfusion during cardiopulmonary bypass in renal renal injury after coronary revascularization: implications on operative outcome. Crit Care Med. 2005:33(8):1749-56.

21. Rossert J, Fouqueray B, Boffa JJ. Anemia management and the delay of chronic renal failure progression. J Am Soc Nephrol. 2003;14(7 Suppl 2):S173-7.

22. Kuriyama S, Tomonari H, Yoshida H, Hashimoto T, Kawaguchi Y, Sakai O. Reversal of anemia by erythropoietin therapy retards the progression of chronic renal failure, especially in nondiabetic patients. Nephron. 1997;77:176-85

23. Yoo YC, Shim JK, Kim JC, Yo YY, Lee JH, Kwak YL. Effect of single recombinant human erythropoietin injection on transfusion requirements in preoperatively anemic patients undergoing valvular heart surgery. Anesthesiology. 2011;115:929-37.

24. Song YR, Lee T, You SJ, Chin HJ, Chae DW, Lim C, et al. Prevention of acute kidney injury by erythropoietin in patients undergoing coronary artery bypass grafting: a pilot study. Am J Nephrol. 2009;30(3):253-60.

25. Mehta RL, Kellum JA, Shah SV, Molitoris BA, Ronco C, Warnock DG, et al. Acute Kidney Injury Network: report of an initiative to improve outcomes in acute kidney injury. Crit Care. 2007;11:R31.

26. Bone RC, Balk RA, Cerra FB, Dellinger RP, Fein AM, Knaus WA, et al. Definitions for sepsis and organ failure and guidelines for the use of innovative therapies in sepsis. The ACCP/SCCM Consensus Conference Committee. American College of Chest Physicians/Society of Critical Care Medicine. Chest. 1992;101:1644-55.

27. Health Research Authority, Research legislation and governance. http:// www.hra.nhs.uk/resources/research-legislation-and-governance/governancearrangements-forresearch-ethics-committees/. Accessed on 8th January 2016.

28. Hales M, Solez K, Kjellstrand C. The anemia of acute renal failure: association with oliguria and elevated blood urea. Ren Fail. 1994;16(1):125-31.

29. Evans RG, Goddard D, Eppel GA, O'Connor PM. Factors that render the kidney susceptible to tissue hypoxia in hypoxemia. Am J Physiol Regul Integr Comp Physiol. 2011;300(4):R931-40.

30. Darby PJ, Kim N, Hare GM, Tsui A, Wang Z, Harrington A, et al. Anemia increases the risk of renal cortical and medullary hypoxia during cardiopulmonary bypass. Perfusion. 2013;28(6):504-11.

31. Bellomo R, Mârtensson J, Kaukonen KM, Lo S, Gallagher M, Cass A, Myburgh J, Finfer S: Randomized Evaluation of Normal versus Augmented Level Replacement Therapy Study Investigators and the Australian and New Zealand Intensive Care Society Clinical Trials Group. Epidemiology of RBC transfusions in patients with severe acute kidney injury: Analysis from the randomized evaluation of normal versus augmented level study. Crit Care Med. 2015; PMID:26619086.

32. Hu SL, Said FR, Epstein D, Lokeshwari M. The impact of anemia on renal recovery and survival in acute kidney injury. Clin Nephrol. 2013;79(3):221-8.

33. Leal-Noval SR, Munoz-Gomez M, Jimenez-Sanchez M, Cayuela A, Leal-Romero M, Puppo-Moreno A, et al. Red blood cell transfusion in non-bleeding critically ill patients with moderate anemia: is there a benefit? Intensive Care Med. 2013;39(3):445-53.

34. Moore E, Bellomo R. Erythropoetin (EPO) in acute kidney injury. Ann Intensive Care. $2011 ; 1(1): 3$

\section{Submit your next manuscript to BioMed Central and we will help you at every step:}

- We accept pre-submission inquiries

- Our selector tool helps you to find the most relevant journal

- We provide round the clock customer support

- Convenient online submission

- Thorough peer review

- Inclusion in PubMed and all major indexing services

- Maximum visibility for your research

Submit your manuscript at www.biomedcentral.com/submit
Biomed Central 